Nadia M. AL-Skakir BDS, MSc ( Lec.)

Neam N. Al-Yousifany B.D.S., M.Sc. (Asst. prof.)

Maha A. Al-Murad BDS, MSc ( Asst Lec.)

Saif M. AL-Skakir B.D.S.(Dentist)

\section{Bond Strength Between Resin Compo- site and Glass Ionomer ( An in Vitro Study)}

\author{
Department of Conservative Dentistry \\ College of Dentistry, University of Mosul
}

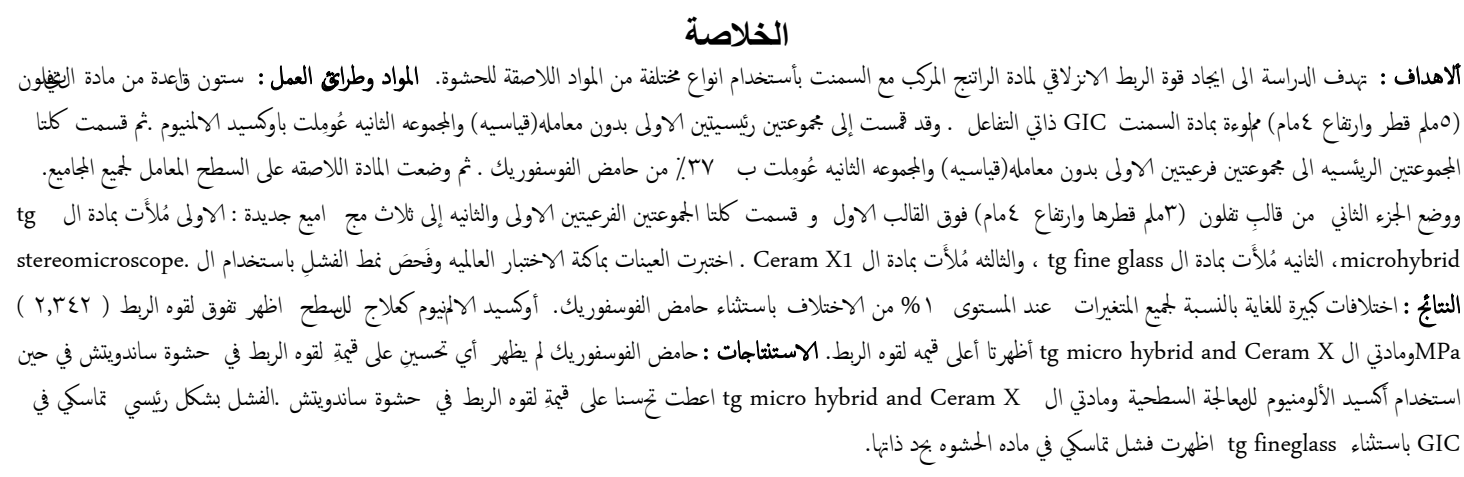

\section{ABSTRACT}

Aims: The aim of this study was to evaluate the shear bond strength of the resin composite to glass ionomer cement (sandwich technique), using different types of bonding agents. Materials and Methods: Sixty Teflon mold of (5mm in diameter and $4 \mathrm{~mm}$ in height) filled with a based type of light cured glass ionomer cement, cured for (40 seconds), randomly assigned into three groups $(\mathrm{n}=20$ ) for bonding with different adhesive materials, (Single Bond, i- bond, and Te-Econom). The bonding applied for ( 15 seconds ). Second split of Teflon mold ( $3 \mathrm{~mm}$ in diameter and $4 \mathrm{~mm}$ in height ) placed on to the prepared specimen filled with a Tetric Ceram composite resin (shade A2) , cured for (40 seconds), the samples stored in distilled water at $37^{\circ} \mathrm{C}$ for $24 \mathrm{~h}$, then thermocycled water for ( 300 cycles) at $\left(55 \pm 2^{\circ} \mathrm{C}\right.$ and $\left.5 \pm 2^{\circ} \mathrm{C}\right)$ with a dwell time of (30 seconds). The bond strength measured by using Universal Testing Machine with a Knife edge head placed at the interface between glass ionomer cement and composite at a cross head speed of $0.5 \mathrm{~mm} / \mathrm{min}$. The modes of fracture were examined by a stereomicroscope at 20X magnification. Results :The data were analyzed using (ANOVA) followed by Duncan's Multiple Range Test at 5\%.The Single bond total-etching adhesive material showed superior bond strengths than all the other materials tested . i- bond is statistically different and showed intermediary values. The TE-Econom showed the lowest shear bond strength rates and was inferior to the Single bond one. The failures were mainly adhesive fracture for both TE-Econom and Single bond adhesive materials, except for i-bond that showed $60 \%$ mixed failure. Conclusions: With the limitation of this in vitro study, the high bond strength for the total- etch (Single Bond) bonding agent not mean that self- etch adhesive systems inferior to total -etch bonding, so further studies are needed to agree that total- etch bonding agents was the better form the clinical point of view. The failures were mainly adhesive for Single Bond and TE-Econom bonding agents and mixed failure for i-bond self- etch bonding systems and this dependent on the types of different bonding agents were used in the present study. Key words: bond strength, adhesive material, glass ionomer cements, resin composite.

Al-Skakir NM, Al-Yousifany NN, Al-Murad MA, Al-Skakir SM . Bond Strength Between Resin Composite and Glass Ionomer ( An in Vitro Study). Al-Rafidain Dent J. 2010; 10(2):281-286.

Received: 27/1/2009

Sent to Referees: $16 / 2 / 2009$ 


\section{INTRODUCTION}

Some dental researchers and clinicians have advocated the use of glass-ionomer cement as a lining under resin composite restorations $^{\text {(1) }}$

Much attention has been focused on the development of adhesive systems that will effectively bond resin composite to dentin $^{(2)}$ Several dentin bonding adhesives have been developed for the restoration of lost tooth structure ${ }^{(3,4)}$ The major goals of using dentin bonding agents are to enhance the bonding strength between the resin and the tooth structure, increase the retention of the restoration, reduce the microleakage across dentin-resin interface, and scatter the occlusal stress ${ }^{(5)}$

Dental adhesives are used for a wide variety of applications. They are available as etch-and-rinse systems (also known as "total-etch" systems) and self-etch systems. Both systems result in etching of the tooth surface, and mechanical and/or chemical retention of the restoration or device upon curing of the adhesive. The adhesive system selected has implications for the technique used as well as for the quality of the bonding ${ }^{(6)}$

Glass ionomer cements have several advantages such as fluoride release, ${ }^{(7-11)}$ adhesion to mineralized dental tissue, ${ }^{(12)}$ and a coefficient of thermal expansion comparable to that of tooth structure ${ }^{(13)}$. Because of these favorable properties, Mclean and Wilson ${ }^{(14)}$ proposed the placement of glass ionomer cement on dentin prior to the application of a resin composite. This restorative method is commonly referred to as the sandwich technique. This procedure makes optimal use of the adhesive properties and biocompatibility of the glass ionomer cement and the desirable surface and esthetic appearance of composite resin.

Among the factors that may affect the bond strength between a resin composite and a glass ionomer cement are the tensile strength of the cement, itself, the adhesive system and the composite resin, employed ${ }^{(15)}$, the type of glass ionomer cement ${ }^{(16)}$,the surface treatment of the cement ${ }^{(17)}$ and shear strength; which defined as the force per unit area that would listed one portion of the material to slide against another portion ${ }^{(18)}$, shear bond strength is commonly used to test the strength of bonding materials.

Several studies have been done on the effectiveness of self- etching materials on the adhesion of composite to glass ionomer cement. However controversial results have been reported about the bonding performance of adhesives ${ }^{(19-21)}$. The aim of this study was to evaluate the shear bond strength( using different types of bonding materials), of a resin composite to the glass ionomer cement(sandwich technique).

\section{MATERIALS AND METHODS}

Sixty specimens of a light cured base glass ionomer cement (FREEDOM SDI Bayswater, Victoria 3153, Australia ) were prepared using Teflon mold, the mold had a central hole measuring $(5 \mathrm{~mm})$ in diameter and $(4 \mathrm{~mm})$ in height, each hole was filled with glass ionomer cement using an incremental technique with a plastic instrument and covered with microscopic slid to produce a smooth surface and to facilitate light curing, each specimen was cured for (40 seconds) according to manufacture instruction. Light cure unit ( Translux ${ }^{\circledR}$ curing unit. Dental curing light unit, Europe ) was used for all curing procedures in the present study.

The samples were randomly assigned to three groups $(\mathrm{n}=20)$ for bonding with three different adhesive systems:

Single Bond (3M ESPE ST. PauL. Minn).

i- bond (Heraeus Kulzer,Hanau, Germany).

Te-Econom (Ivoclor - vivadent AG schaan, Liechstein).

Bonding materials was applied and cured for ( 15 seconds ) with light brushing motion according to the manufacturer instructions .Second split of Teflon mold ( $3 \mathrm{~mm}$ in diameter and $4 \mathrm{~mm}$ in height) was placed on to the prepared specimen. A Tetric Ceram composite resin shade A2 , Ivoclar vivadent, AGFL-anau schann/ Leichtenstein), was inserted into the mold incrementally, and cured for (40 seconds) (according to the manufacturer's instructions ) from the top of the specimens. After curing the second split mold was removed. 
The samples were stored in distilled water at $37^{\circ} \mathrm{C}$ for $24 \mathrm{~h}$, thermo-cycled for ( 300 cycles), each a cycle consisted of 30 seconds at $55 \pm 2^{\circ} \mathrm{C}$ and $5 \pm 2^{\circ} \mathrm{C}$ with a dwell time of 30 seconds ${ }^{(22)}$.

The bond strength between the glass ionomer cement and composite was measured by using Universal Testing Machine with a Knife edge head placed at the interface between glass ionomer cement and composite at a cross head speed of $0.5 \mathrm{~mm} / \mathrm{min}^{(23)}$.

The modes of fracture were examined by a stereomicroscope ( Zeiss, MC 63A, Germany) at 20X magnification power.

Data were tabulated and statistically analyzed. They were analyzed using analysis of variance (ANOVA) followed by Duncan's Multiple Range Test at 5\% level of significance to indicate if there were any statistical difference in shear bond strength of the three groups.

\section{RESULT}

Table (1) shows the mean shear bond strengths (in MPa) for the different groups, as well as the results of the Duncan's Multiple Range Test. Figure (1) explain the comparison of mean values between the different groups. The Single Bond totaletching adhesive material showed superior bond strengths than all the other materials tested, i-bond self-etching adhesive is statistically different and showed intermediary values. The TE- Econom (all-in-one adhesive) showed the lowest shear bond strength that inferior to the Single bond one.

Table(1) Mean bond strength ( \pm standard deviation) obtained for the different groups and the results of the Duncan test

\section{Shear strength (MPa)}

\begin{tabular}{cccc} 
& SD & Mean & \\
\hline A & 0.11 & 4.14 & Single bond \\
B & 0.23 & 3.69 & i- bond \\
C & 0.03 & 2.90 & TE- Econom
\end{tabular}

Different letters mean significant difference at $\mathrm{p} \leq 0.05$

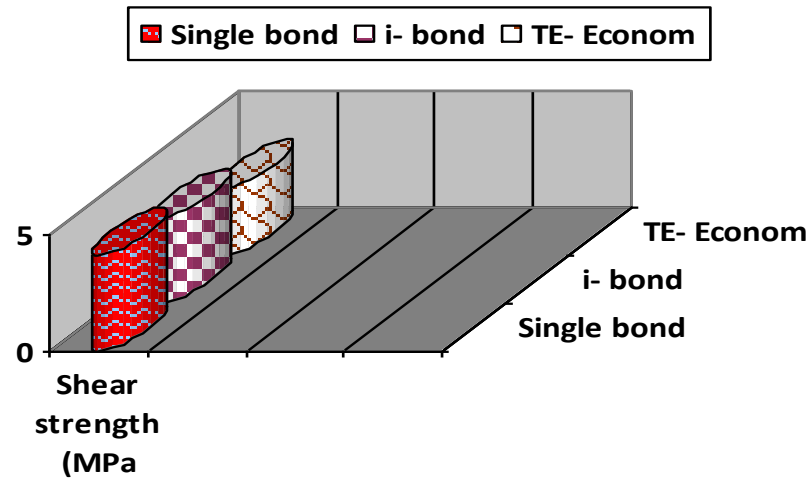

Figure (1): Comparison of mean shear bond strength values among different groups 
The mode of failures were mainly adhesive type of fracture for Single Bond and TE- Econom adhesive materials, while i- bond showed $60 \%$ mixed failure, Table (2) .

Table(2) Mode of fracture (failure) in percentages for : (Single bond, i- bond,TE- Econom).

\begin{tabular}{ccc}
\hline Mixed & Adhesive & Adhesive system \\
\hline $20 \%$ & $80 \%$ & Single bond \\
$60 \%$ & $40 \%$ & i- bond \\
$10 \%$ & $90 \%$ & TE- Econom \\
\hline
\end{tabular}

\section{DISCUSSION}

The laminate or "sandwich" technique has been suggested primarily for lessening microleakage. The bond strength between the glass-ionomer cement and resin composite is highly dependent on the adhesive systems used, the methods of handling, types of composite resin and the glass ionomer cement employed. ${ }^{(1,24,25)}$.

The high bond strength with the total etch Single Bond achieved on the present study, may be due to unfilled nature of the adhesive with lack of nanofillers which may reduce shrinkage and increase rigidity and bonding of the adhesive, thus acting as an intermediate shock absorber that responsible for high bonding. The current study agree with the study by Crim and Deliperi et al., who stated that the unfilled adhesive with lack of nanofillers, responsible for high bonding strength of total- etch adhesive agents ${ }^{(26,27)}$.

The one- bottle self-etching ( $\mathrm{i}$ - bond) systems, represents the latest simplification of adhesive systems that showed low bonding strength in the present study comparing to total etch and this may be due to excessive water content of the adhesive system which dilute the primer of the adhesive and reduce its effectiveness. So water-based adhesive systems may result in lower bond strength that is due to incomplete polymerization of the monomers ${ }^{(28,29)}$.

Self -etching adhesive systems are undergoing rapid advancements and the simplification in the adhesive technique became a major requirements in current practice but, the degree of the bonding ability is still questionable.
Self-etching adhesives, by virtue of their self-etching nature, contain acidic monomers and water. The effectiveness of a self-etch adhesive system depends on multiple factors. The result of this study was in agreement with Moura et al., who demonstrated that self- etch systems showed lower bond strength compared to total-etch bonding agents ${ }^{(30)}$.Shinohara et al., concluded that low bond strength with questionable bonding effectiveness was achieved with self-etching adhesive systems (31). Nakabayashi and Takarada noticed that the hydrophilic nature and evaporable solvent responsible for low bonding ability of the self- etching systems ${ }^{(32)}$.

In the present study, the bond strength of all-in-one adhesive TE-Econom differ significantly from that of self-etching bonding agent and this may be due to the hydrophilic nature of monomers and the presence of evaporable solvent of TE-Econom system ${ }^{(33)}$. Elghandour and Elgezawi demonstrated the same result that were a significant difference in shearing strength between TE- Econom of all-in-one adhesive system and self- etching bonding agents ${ }^{(33)}$.

The failures were mainly adhesive within the TE- Econom and Single bond adhesive materials, except $60 \%$ for i- bond self-etching adhesives that showed mixed failure and this can be explained by difference in the composition of the bonding agents and the methodology used as stresses within the bonding interface in shear bond test is highly dependent on test geometry and loading configuration employed . This finding is in agreement with Van Noor et al.,and Borges et al., who concluded that the 
adhesive failure occur more frequently with Single Bond and TE- Econom adhesives while failures were mainly mixed for i-bond adhesive ${ }^{(34,35)}$.

The high bond strength for total- etching agents make it superior to self-etching bonding to be used clinically, but farther studies are needed about microleakage, sealing ability, biocompatibility and acidity.

\section{CONCLUSIONS}

1-The limitation of this in vitro study, the high strength was for Single Bond while i- bond and TE- Econom were not differ significantly.

2-The high bond strength for the totaletch (Single Bond) bonding agent not mean that self- etch adhesive systems inferior to total - etch bonding, so further studies are needed to agree that total- etch bonding agents was the better form the clinical point of view.

3-The failures were mainly adhesive for Single Bond and TE- Econom bonding agents and mixed failure for i- bond selfetch bonding systems and this dependent on the types of adhesive bonding agents were used in the present study.

\section{REFERENCES}

1. Bowen RL, Marjenhoff WA. Dental compost / glass ionomer cement: the materials. Adv Dent Res . 1992; 6:44-49.

2. Andreasus SB. Liquid versus gel etchants on glass ionomers: their effects on surface morphology and shear bond strengths to composite resins. J Am Dent Assoc .1987;114: 157-158.

3. Dumsha TC, Sydiskis RJ. Cytotoxcity testing of dentin bonding system. Oral Surg Oral Med Oral Pathol . 1985;59:637-641.

4. Townsend RD, Dunn WJ. The effect of saliva contamination on enamel and dentin using a self-etching adhesive. J Am Dent Assoc. 2004; 135(7) :895-901.

5. Douglas WH. Clinical status of dentin bonding agents. J Dent. 1989;17:209215.

6. Latta MA. Clinical Perspectives on Current Dental Adhesives. A PeerReviewed Publication,2002.

7. BarKemeier WW, ErickcKson RL. shear bond strength of composite to enamel and dentin using Scotchbond MultiPurpose. Am J Dent .1994;7:175-179.

8. Shomalzaden M. A Comparative study on the shear bond strength between a two-paste base-catalyst adhesive system and no-mix primer-paste adhesive system. Phili J Orth.2004; :39-50

9. Cim GA, Garcia- Godoy F. Microleakage : the effect of storage and cycling duration. J Prosthet Dent. 1987;57:574576.

10.DeSchepper EJ, Berry EA, Cailletau JG. Fluoride release from light-cured liners. Amer J Dent .1990;3:97-100.

11.Forsten L. Fluoride release from a glass ionomer cement. Scand J Dent Res.1977;85:503-504.

12. Fuss J, Mount GJ, Makinson OF . The effect of etching on a number of glass ionomer cements. Aust Dent J .1990;35:338-344.

13. Garcia-Godoy F. Glass ionomer materials in class II composite resin restorations: to etch or not to etch?.Quint Int.1988;19:241-242.

14. Wilson AD, Kent BE. The glass ionomer cement, a new translucent dental filling material. J Appl Chem Biotechnol.1971;21:313.

15.McLeanJW, Powis DR, Prosser HJ. The use of glass ionomer cement in bonding composite resin to dentine. Braz Dent J.1985;158:410-414.

16. Oilo G, Um CM. Bond strength of glass ionomer cement and composite resin combinations. Quint Int.1992;23:633639.

17. Craig RG. Dental Materials: properties and manipulation. St. Louis.1992;Mosby-year book,17-19. Quint Int.1988;19:241-242.

18. Mount GJ .The tensile strength of the union between glass ionomer cements and various composite resins. Aust Dent J.1989;34:136-146.

19.Titley K, Caldwell R, Kulkami G. Factors that affect the shear bond strength of multiple component and single bottle adhesives to dentin. Am J Dent. 2003;16:120-124.

20. Hayakawa T, Kikutake K, Nemoto K. Influence of self etching primer treatment on the adhesion of resin composite to polished dentin and enamel .Dent Mater. 1998;14:99-105 
21. Prati C, Chersoni S, Mongiorgi R, Pashley DH. Resin-infiltrated dentin layer formation of new bonding systems. Oper Dent. 1998;23:185-194.

22. Malmstom H, Schlueter N, Roach $T$, Moss ME. Effect of thickness of flowable resins on marginal leakage in class II composite restorations. Oper Dent. 2002;27 :317-328.

23.Ribeirao $P$. Effect of refrigeration on bond strength of self -etching adhesive systems. Braz Dent J.2006;17(3).

24. Mount GJ. The tensile strength of the union between various glass ionomer cements and various composite resins. Aust Dent J. 1989;34:136-46.

25. Reeves GW, Fitchie JG, Scarbrough AR, Hembree JH. Microleakage of gluma bond, scotchbond 2 and a glass ionomer/composite sandwich technique. Am J Dent .1990;3:195- 198.

26. Crim GR. Influence of bonding agents and composites on Microleakage . J Prosthet Dent. 2003;6 (1) :3-5.

27.Deliperi S, Bardwell DN, Pafathanasion A, Perry R. Microleakage of resin bases liner materials and condensable composites using filled and unfilled adhesives . Am J Dent. 2003;16:351-355.

28. Tay FR, Sano OH, Carvalho RM, Pashley DH. An ultra structural study of the influence of the acidity of self-etching primers and smear layers thicken on the bonding to intact dentin. J Adhes Dent. $2006 ; 2$ :83-98.

29.Al- Nahedh H, Ateyah N. Effect of different bonding condition on the shear bond strength of two compomer to Bovine Dentin. J Cont prac.2006;7 (4).

30.Moura SK, Santos JFF, Ballester RY. Morphologlass ionomer cement al characterization of the tooth/ adhesive interface. Braz Dent J.2006; 17(3):179-185.

31.Shinohara MS, Oliveira MT, Diltipolito V, Marcelo G,Goes MF. SEM analysis of the acid-etched enamel patterns promoted by acidic monomers and phosphoric acids. J Appl Oral Sa.2006; 14(6).

32.Nakabayashi N,Takarada K. Effect of HEMA on bonding to dentin. Dent Mater. 1992;8:125-30.

33.Elghandour AI, Elgezawi FM. Influence of application technique on the shear bond strength of total-etch versus self etch bonding systems to human dentin. Offi J Egyp Dent Asso.2006;52(4):1931.

34. Van Noor R, Noroozi S, Howard IC, Cardew GE. A critique of bond strength measurements. J Dent. 1989;17:61-67.

35. Borges GA, Spohr AM, Sobrinho LC, Correr AB, Borges LH. Effect of refrigeration on bond strength of self- etching adhesive systems. Braz Dent J .2006; 17 (3):186-190. 